\title{
A influência da gestão de pessoas nas organizações diante dos impactos ambientais e da sustentabilidade
}

\section{The influence of people management in organizations in the face of environmental impacts and sustainability}

La influencia de la gestión de personas en las organizaciones frente a los impactos ambientales y la sostenibilidad

\section{Alessandre da Silva ${ }^{1}$ Cristina Veloso de Castro ${ }^{2}$ Juliana Heloisa Pinê Américo-Pinheiro³}

${ }^{1}$ Mestre em Ciências Ambientais pela Universidade Brasil (UB). E-mail: alessandre.ads@gmail.com, Orcid: http://orcid.org/0000-0002-1477-511X

${ }^{2}$ Doutora em Sistema Constitucional de Garantias de Direito pelo Instituto Toledo de Ensino (ITE). Professora titular do Programa de Pós-Graduação Stricto Sensu em Ciências Ambientais da Universidade Brasil (UB).

E-mail: cristinavelosocastro@gmail.com, Orcid: http://orcid.org/0000-0002-3016-0326

${ }^{3}$ Doutora em Aquicultura pela Universidade Estadual Paulista Júlio de Mesquita Filho (UNESP). Professora titular do Programa de Pós-Graduação Stricto Sensu em Ciências Ambientais da Universidade Brasil (UB).

E-mail: americo.ju@gmail.com, Orcid: http://orcid.org/0000-0001-6252-828X 
Resumo: A presente pesquisa descreve qual a importância da gestão de pessoas dentro das organizações, voltada às questões ambientais, assim como visa à possibilidade de identificar qual a melhor forma de conduzir esses profissionais para que tenham hábitos sustentáveis, ou seja, uma educação ambiental empresarial voltada para a qualificação profissional, pessoal e também às questões que envolvam técnicas e comportamentos para minimizar os impactos ambientais causados pelas empresas. Trata-se de uma pesquisa descritiva que envolve um estudo bibliográfico, no qual se procurou identificar a visão dos estudiosos acerca da problemática apresentada. Problemática essa que se refere ao modo de como os profissionais dos mais diversos segmentos empresariais lidam com as questões ambientais e de sustentabilidade ambiental.

Palavras-chave: educação ambiental empresarial; sustentabilidade ambiental responsável; gerenciamento e capacitação de pessoas.

\begin{abstract}
The present research describes the importance of people management within organizations, focused on environmental issues, as well as the possibility of identifying the best way to lead these professionals to have sustainable habits, that is, a business environmental education aimed at professional qualification, personal and also focused on issues involving techniques and behaviors to minimize the environmental impacts caused by companies. It is a descriptive research that involves a bibliographical study, where it was tried to identify the view of the scholars about the problematic presented. This problematic refers to the way in which professionals from the most diverse business segments deal with environmental and environmental sustainability issues.
\end{abstract}

Keywords: corporate environmental education; responsible environmental sustainability; people management and training.

Resumen: La presente investigación describe la importancia de una gestión de las personas dentro de las organizaciones, orientada a las cuestiones medioambientales, así como la posibilidad de identificar cuál es la mejor manera de conducir a estos profesionales para que tengan hábitos sostenibles, es decir, una educación ambiental empresarial orientada a la cualificación profesional, personal y también orientada a cuestiones que involucran técnicas y comportamientos para minimizar los impactos ambientales causados por las empresas. Se trata de una investigación descriptiva que involucra un estudio bibliográfico, donde se buscó identificar la visión de los estudiosos acerca de la problemática presentada. La problemática se refiere al modo en que los profesionales de los más diversos segmentos empresariales se ocupan de las cuestiones ambientales y de sostenibilidad ambiental.

Palabras clave: educación ambiental empresarial; sostenibilidad ambiental responsable; gestión y capacitación de personas. 
A influência da gestão de pessoas nas organizações diante dos impactos ambientais e da sustentabilidade

\section{INTRODUÇÃO}

A gestão de pessoas é uma importante ferramenta dentro das organizações, sendo um aglomerado de procedimentos, estratégias e métodos voltados para a potencialização do capital humano e, assim, garantia de que seus colaboradores sejam capazes de se desenvolver na sua forma mais completa, fazendo com que as suas competências e habilidades criem fontes de melhorias e de transformações dentro das organizações.

Teve seu surgimento a partir do ano de 1900, na era industrial clássica, com Frederick Taylor, mas, desde a Revolução Industrial, a gestão de pessoas vem passando por constantes transformações, isso para poder atender às necessidades das empresas, dos colaboradores e da sociedade como um todo.

Tal revolução proporcionou avanços e melhorias para a sociedade, mas algumas situações ruins também fizeram parte desse cenário. Quanto aos benefícios: o surgimento de novas tecnologias, o avanço nas máquinas de produção, rápido desenvolvimento nos meios de comunicação, criação de sindicatos e garantias do direito do trabalho.

Em relação aos malefícios da época, temos: o êxodo rural, aumento do número de desempregados, crescimento desordenado das cidades, situações críticas ao meio ambiente devido à poluição e condições precárias de trabalho.

A globalização impõe mudanças imediatas, pois o cenário empresarial está passando por acentuadas transformações, em que se exigem propostas para a qualificação profissional e maior zelo dos recursos ambientais, e as empresas, por meio de incentivos, desenvolvem novas formas de lidar com o meio ambiente, a fim de garantirem a sustentabilidade ambiental por meio da sustentabilidade empresarial e a geração do bem-estar para a sociedade.

A educação ambiental se faz necessária dentro das organizações, no que se refere a preparar o trabalhador para uma conduta ambiental responsável, favorecendo a prática ética empresarial junto do meio ambiente e a aplicação dessa educação fora do local de trabalho. 
O presente estudo tem por objetivo verificar se há a necessidade de uma gestão de pessoas voltada para o senso da educação ambiental empresarial, a fim de minimizar os impactos ambientais decorrentes das ações empresariais, e também como essa gestão poderia atuar de forma ativa junto à sociedade, para que uma educação ambiental empresarial seja veiculada de forma mais dinâmica e ativa.

\section{GESTÃO DE PESSOAS: CONCEITOS E HISTÓRICO}

No início do século XX, com a Revolução Industrial, as organizações empresariais perceberam a necessidade de uma nova política e de novas maneiras para lidar com as pessoas e com suas formas de trabalho. Assim, com o estudo da Teoria Clássica da Administração e a Teoria da Burocracia, foi possível dar início a uma nova forma e até mesmo padronização da gestão de pessoas.

Com isso, as empresas da época tiveram como objetivo a estruturação do departamento de pessoal, na qual este mesmo setor foi o responsável por regulamentar e implementar diretrizes para o funcionamento das organizações.

A gestão de pessoas é composta por princípios e práticas para desenvolver as competências exigidas para a permanência dos colaboradores no ato de suas funções dentro das organizações, a fim de garantir o desenvolvimento do capital humano.

De acordo com o quadro 1, é possível constatar a evolução da gestão de pessoas no Brasil e, a seguir, como essa evolução é entendida. 
A influência da gestão de pessoas nas organizações diante dos impactos ambientais e da sustentabilidade

Quadro 1 - Linha do tempo da evolução da gestão de pessoas no Brasil

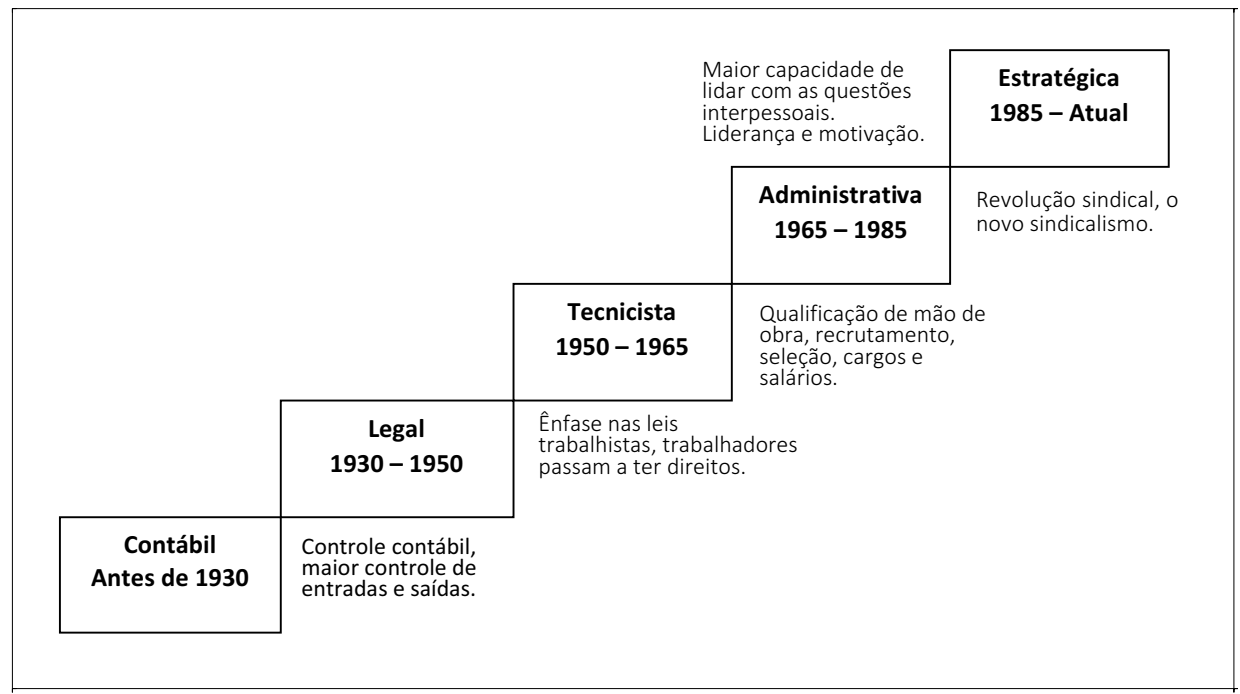

Fonte: Chiavenato (2009), adaptado pelo autor (2019).

O capital humano é intangível e não pode ser gerenciado da mesma maneira que as empresas gerenciam cargos, produtos e tecnologias. Uma das razões para isso é que são os funcionários, e não a empresa, os detentores do capital humano. Ao saírem funcionários valiosos de uma empresa, eles levam consigo seu capital humano, e qualquer investimento que a empresa tenha feito no treinamento e desenvolvimento dessas pessoas fica perdido para ela (BOHLANDER; SNELL; SHERMAN, 2005, p. 9).

De acordo com o quadro 2, a seguir, os cenários estão se diferenciando de forma bem clara, uma vez que o sistema utilizado no passado não mais se aplica, devido às necessidades e exigências do presente, com pessoas mais criteriosas, sistemas mais precisos e a necessidade de urgência. 
Quadro 2 - Processos da gestão de pessoas

\begin{tabular}{|c|c|c|}
\hline \multirow{6}{*}{ 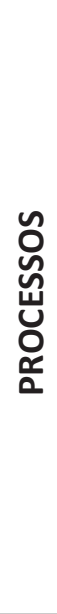 } & De Agregar Pessoas & \begin{tabular}{|l|} 
- Recrutamento \\
- Seleção \\
\end{tabular} \\
\hline & De Aplicar Pessoas & $\begin{array}{l}\text { - Desenho de Cargos } \\
\text { - Avaliação do Desempenho } \\
\end{array}$ \\
\hline & De Recompensar Pessoas & $\begin{array}{l}\text { - Remuneração } \\
\text { - Benefícios } \\
\end{array}$ \\
\hline & De Desenvolver Pessoas & $\begin{array}{l}\text { - Treinamento } \\
\text { - Mudanças } \\
\text { - Comunicações } \\
\end{array}$ \\
\hline & De Manter Pessoas & $\begin{array}{l}\text { - Disciplina } \\
\text { - Higiene, Segurança e Qualidade de Vida } \\
\text { - Relações com Sindicatos }\end{array}$ \\
\hline & De Monitorar Pessoas & $\begin{array}{l}\text { - Banco de Dados } \\
\text { - Sistemas de Informações Gerenciais }\end{array}$ \\
\hline
\end{tabular}

Fonte: Elaborado pelos autores (2019).

Segundo Marras (2005, p. 128), “é necessário que as empresas considerem, principalmente, a importância dos seus ativos intangíveis, como o capital intelectual e as competências profissionais dos seus trabalhadores".

A partir da fase tecnicista (1950), a gestão de pessoas vem promovendo transformações e, com isso, gerando maior competitividade entre as organizações. Nesse sentido, é possível evidenciar que a prática da vantagem competitiva pode ser influenciada pelo capital humano e intelectual existente em uma organização, talvez pelo fato de que a criação e a inovação são características exclusivas do ser humano.

Talvez seja possível ser indiferente em relação às questões para a elaboração de estratégias, mas a gestão de pessoas deve se preocupar com o indivíduo dentro da organização, desde a sua contratação até o seu desligamento. Uma gestão promissora não está preocupada com os investimentos desprendidos para a qualificação de pessoas, mas sim com o retorno que esse investimento vai proporcionar. Pessoas capacitadas são mais felizes para desempenharem suas funções profissionais, o que contribui para um bom andamento nas condições empresariais.

O sistema organizacional vem passando por adaptações devido à globalização; o sistema rígido e rudimentar do passado busca se adequar 
A influência da gestão de pessoas nas organizações diante dos impactos ambientais e da sustentabilidade

ao novo sistema, surgindo, assim, a flexibilidade. Todas as empresas são compostas por grupos de pessoas que vislumbram alcançar um objetivo comum, porém pessoas e empresas possuem objetivos próprios. A harmonia e o equilíbrio desses objetivos dependem dos incentivos ofertados pelas empresas como moeda de troca para que recebam a contribuição das pessoas.

\subsection{Gestão de pessoas na educação ambiental empresarial}

Sabe-se que a gestão de pessoas está diretamente ligada à questão da capacitação e qualificação de pessoas, para que estas sejam capazes de desempenhar suas funções profissionais de maneira eficiente, a fim de alcançar a eficácia organizacional.

É por isso que transformar a experiência educativa em puro treinamento técnico é amesquinhar o que há de fundamentalmente humano no exercício educativo: o seu caráter formador. Se se respeita a natureza do ser humano, o ensino dos conteúdos não pode dar-se alheio à formação moral do educando. Educar é substancialmente formar (FREIRE, 2011, p. 37).

A gestão de pessoas deve estar em constante harmonia com a gestão ambiental, para que os resultados da organização empresarial possam ser alcançados.

Segundo Tachizawa (2005), uma organização só é efetiva nas questões socioambientais quando se mantém com uma postura socialmente responsável no alcance do desenvolvimento econômico-social.

Seria coerente a prática da educação ambiental por meio das organizações, de forma que os trabalhadores possam receber treinamentos para o seu aprendizado, relacionados às questões ambientais, sobre quais os riscos a que o meio ambiente está exposto com a má conduta de responsabilidade ambiental provocada pelo homem ou pela organização da qual ele é colaborador e, também, sobre os riscos que o homem sofre em caso de colapso ambiental em virtude das ações devastadoras ao meio ambiente.

Para Dias (2011), para que não seja formado um gueto ambiental dentro das organizações, faz-se necessário o desenvolvimento de progra- 
mas junto da gestão de pessoas, para que a atividade ambiental possa ser concretizada e assim molde a nova postura das pessoas que compõem as organizações.

Já que a prática da gestão de pessoas é desenvolver a capacidade profissional e intelectual dos seus trabalhadores, a aplicabilidade de uma educação ambiental pode contribuir aos efeitos de conscientização de como usar os recursos naturais de modo racional e também de como conservar o meio ambiente.

Conforme descrito em Década das Nações Unidas da Educação para o Desenvolvimento Sustentável 2005-2014 (2005), “a educação ambiental é o principal agente de transformação para o desenvolvimento sustentável, aumentando a capacidade das pessoas de transformarem sua visão de sociedade em realidade". Assim, a educação ambiental vem complementar as propostas para uma educação sustentável. Segundo o documento:

Educação ambiental é uma disciplina bem estabelecida que enfatiza a relação dos homens com o meio ambiente natural, as formas de conservá-lo, preservá-lo e de administrar seus recursos adequadamente. Portanto, desenvolvimento sustentável engloba a educação ambiental, colocando-a no contexto mais amplo dos fatores socioculturais e questões sociopolíticas (DÉCADAS..., 2005, p. 46).

Brasil (1999), na Lei Federal n. 9.795/99, define a Educação Ambiental como "processos por meio dos quais o indivíduo e a coletividade constroem valores sociais, conhecimentos, habilidades, atitudes e competências voltadas para o meio ambiente, bem de uso comum do povo, essencial à sadia qualidade de vida e sua sustentabilidade" (MOUSINHO, 2008, p. 349).

Também prevê que as empresas desenvolvam programas de capacitação dos funcionários visando ao controle dos impactos do processo produtivo no meio ambiente e à melhoria do ambiente de trabalho.

De acordo com Mousinho (2008), a educação ambiental é ferramenta indispensável para que haja uma educação nacional ativa sobre as questões ambientais e deve estar presente no processo educativo, tanto formal quanto não formal.

É preciso compreender que a educação ambiental é um recurso que favorece o aprendizado constante e visa afirmar valores contribuindo para 
A influência da gestão de pessoas nas organizações diante dos impactos ambientais e da sustentabilidade

a transformação social e humana, promovendo mudanças de costumes e ações destinados à conservação e preservação do meio ambiente.

Quando internalizado no âmbito da governança empresarial, um processo de Educação Ambiental Empresarial é capaz de gerar empoderamento, sinergia como estratégia de ação, reciprocidade no que tange ao envolvimento de toda a estrutura organizacional, enraizamento para perceber ganhos e contextura para se tornar parte de um todo, visto que ele se torna essência na estrutura organizacional e na implantação de um Programa de Educação Ambiental Empresarial. Quando a EA é incorporada na estrutura de gestão e adotada como estratégia empresarial, ela pode promover a sinergia expressa como um conjunto de forças agindo simultaneamente para um mesmo propósito. Por outro lado, a falha na assimilação conceitual pode gerar a entropia, na qual o indivíduo se volta para si e se retrai. Caso não exista alinhamento e envolvimento, ou a Educação Ambiental não seja consenso conceitual e estratégico na empresa, pode-se desenvolver a incompatibilidade de ideias, de ações, de perspectivas, ocasionando um impacto negativo, a resistência na implantação da Educação Ambiental Empresarial (CASELE, 2015, p. 94-6).

\section{SUSTENTABILIDADE EMPRESARIAL E AMBIENTAL DIANTE DO BEM-ESTAR SOCIAL}

A sustentabilidade ambiental se dá em meio à responsabilidade socioambiental corporativa, em que as organizações empresariais conscientes dos recursos ambientais se estruturam para sanar problemas relacionados ao meio ambiente, promovendo uma gestão de políticas empresariais voltadas para o desenvolvimento e a sustentabilidade não apenas das empresas, mas também envolvendo todo o sistema social onde se encontram.

Quando se fala em sustentabilidade, a ideia que se deve ter é a de uma ação persistente que entrelaça os interesses sociais, econômicos e ambientais (natureza). Em 1987, a WCED (World Commission on Environment and Development - Comissão Mundial sobre Meio Ambiente e Desenvolvimento), formada por membros da Organização das Nações Unidas, introduziu o conceito de "sustentabilidade ambiental", com a iniciativa de unificar países em torno do desenvolvimento sustentável. 
Para o Instituto Ethos (2009), ação sustentável é aquela que assegura a longevidade do negócio e ao mesmo tempo contribui com o desenvolvimento econômico e social, garantindo a estabilidade social e permitindo satisfazer as necessidades da presente geração sem comprometer as futuras gerações.

Nos dias atuais, sustentabilidade pode ser compreendida como a manutenção do equilíbrio ao longo dos tempos, ou seja, é a possibilidade de serem atendidas as necessidades dos seres humanos hoje, sem que sejam comprometidas as gerações futuras.

O termo "sustentabilidade" por anos vem sendo tema de inúmeros debates e discussões na sociedade moderna, pois os impactos sofridos pela conduta do homem e das indústrias causaram incontáveis danos e prejuízos à natureza e, se não for realizada nenhuma ação para reverter esse processo, o bem-estar do ecossistema pode vir a ter perdas ainda maiores e até mesmo irreversíveis.

A figura 1 traz de forma ilustrativa os pilares da sustentabilidade e a relação entre os fatores ambientais, sociais e econômicos:

Figura 1 - Pilares da sustentabilidade

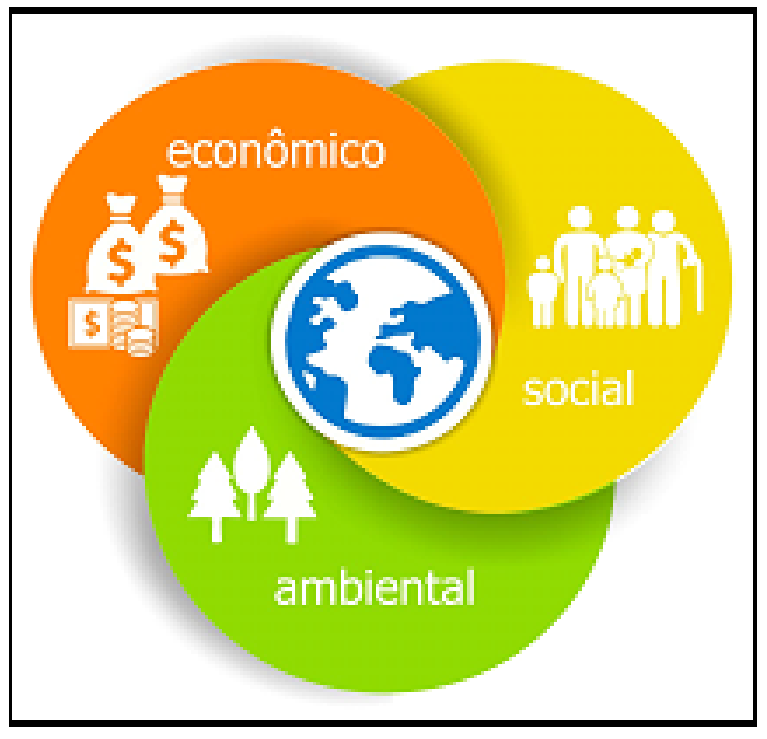

Fonte: https://ecolmeia.org.br/material-para-educacao-ambiental/ tripe-da-sustentabilidade-1-2/. Figura adaptada pelos autores (2019). 
A influência da gestão de pessoas nas organizações diante dos impactos ambientais e da sustentabilidade

Vale ressaltar que tal processo de transição de sistema apenas será fazível por meio da educação ambiental, que favorece o alicerce com bases teóricas para que a sustentabilidade seja alcançada. Pela incorporação das esferas econômica, política, social e ambiental, será possível alcançar o ápice do desenvolvimento sustentável por meio da educação ambiental.

No sentido de conscientização e responsabilidade, o ser humano, ser racional e dotado de habilidades notáveis, precisa entender que a degradação ambiental coloca em risco o equilíbrio do ecossistema e que a sustentabilidade é indispensável a todos.

Seja como for, a visão atual de natureza, potencializada pela tecnologia, herdou o projeto de dominação assentado no dualismo homem-natureza, na qual a última é instrumentalizada em benefício do primeiro. Em outras palavras, universalizou-se a postura - que se tornou dogma - de transformar o conhecimento da natureza em instrumento de domínio da mesma (RAMOS, 2010, p. 31).

Existe a necessidade de entender que a sustentabilidade é um processo que necessita ser convencionado em logo prazo, para que haja um desenvolvimento sustentável, no qual se faz necessário mudar o presente modelo de gestão de desenvolvimento: o sistema de capitalismo-industrial.

Fica claro que esse sistema de desenvolvimento é importante, porém é indispensável uma nova forma de se obter o progresso com sustentabilidade, ou seja, é preciso desenvolver-se considerando estes conceitos concomitantes aos seres humanos, plantas, animais e a todo o planeta.

A sustentabilidade empresarial está ligada diretamente ao desenvolvimento das empresas e das indústrias. Esse desenvolvimento vem do crescimento da economia mundial, em que não se devem descartar medidas e ações que venham a proteger os aspectos das esferas econômicas, sociais e ambientais.

Ações de sustentabilidade por parte das empresas podem promover um crescimento positivo extraordinário na sua marca e imagem. Com tamanhas fontes de informações existentes, o consumidor se faz conhecedor de qual marca ou produto tem ação sustentável. No Brasil, muitas são as empresas que possuem ações de sustentabilidade para o meio ambiente por meio de legislações e incentivos fiscais, o que garante que 
a sua marca esteja estampada como um diferencial competitivo perante seus concorrentes.

Colaboradores que são preparados para as ações sustentáveis ambientais veiculam os benefícios que suas empregadoras oferecem à sociedade; com isso, a maior ação do marketing acaba sendo por parte do próprio colaborador, orgulhoso pelos serviços e decisões que suas empregadoras oferecem ao meio ambiente.

\section{EDUCAÇÃO AMBIENTAL E DEBATES AMBIENTAIS PROPOSTOS PARA A SUSTENTABILIDADE}

A educação ambiental deve ser vista como um processo ininterrupto, em que o desenvolvimento intelectual do homem será capaz de gerar maiores entendimentos em relação aos inúmeros prejuízos que o meio ambiente vem sofrendo.

Pode-se dar uma definição sobre a educação ambiental afirmando que ela está voltada para a conservação e preservação dos recursos naturais, a fim de promover a sustentabilidade do meio ambiente e garantir que haja maior conscientização sobre a importância de preservar a natureza, não deixando de lado os aspectos políticos, socioeconômicos e ecológicos.

É necessário que a sociedade se inteire das questões ambientais, tendo maior compreensão da necessidade de uma boa relação entre o homem e os recursos oferecidos pela natureza. Assim, a educação ambiental será capaz de promover a formação do cidadão com base nos princípios da sustentabilidade ambiental.

A educação ambiental é um processo que consiste em propiciar às pessoas uma compreensão crítica e global do ambiente, para elucidar valores e desenvolver atitudes que Ihes permitam adotar uma posição consciente e participativa a respeito das questões relacionadas com a conservação e adequada utilização dos recursos naturais, para a melhoria da qualidade de vida e a eliminação da pobreza extrema e do consumismo desenfreado. A Educação Ambiental visa à construção de relações sociais, econômicas e culturais capazes de respeitar e incorporar as diferenças (minorias étnicas, populações tradicionais), à perspectiva da mulher e à liberdade para decidir caminhos alternativos de desenvolvimento sustentável, respeitando os limites dos ecossistemas, substrato de nossa própria possibilidade de sobrevivência como espécie (MEDINA, 1998 apud MEDINA, 2001, p. 17-8). 
A influência da gestão de pessoas nas organizações diante dos impactos ambientais e da sustentabilidade

No intuito de promover e elaborar estratégias para o desenvolvimento socioeconômico, alinhado com a preservação do meio ambiente e uso consciente dos recursos naturais, surgiram as conferências ambientais: discussões voltadas às questões ambientais, promovendo diálogos referentes à valorização do meio ambiente. Somente na década de 1960, Pós-Segunda Guerra Mundial, que tais discussões passaram a ser tratadas com maior vigor.

Cada convenção traz consigo sua particularidade e desafios a serem cumpridos, sempre objetivando envolver o maior número de países para que as problemáticas ambientais e sociais sejam discutidas, estudando as formas de como cada país poderá contribuir para a sustentabilidade ambiental com visão holística mundial.

- Conferência de Estocolmo: em 1972, Estocolmo, Suécia. Surgimento de políticas de gerenciamento ambiental, visando à diminuição dos impactos ambientais negativos.

- Eco-92: em 1992, Rio de Janeiro, Brasil. Criação da Agenda 21, moção para o desenvolvimento sustentável.

- Conferência das Partes - Protocolo de Kyoto: Berlim em 1995, Genebra em 1996 e Kyoto em 1997. Minimização da emissão de gases de efeito estufa na atmosfera.

- Rio+10: em 2002, Joanesburgo, África do Sul. Desenvolvimento sustentável, discussões sobre as questões ambientais e erradicação da pobreza mundial. - Rio+20: em 2012, Rio de Janeiro, Brasil. Reforçando os compromissos das conferências anteriores com o desenvolvimento sustentável.

Os principais líderes mundiais reuniram-se nas conferências sobre o meio ambiente em torno de temas de extrema importância tanto para a preservação da natureza quanto ao desenvolvimento sustentável. Muitas foram as ações para a conscientização da sustentabilidade ambiental. Porém vale lembrar que todas essas ações não foram feitas sozinhas, houve a necessidade da gestão do homem, ou seja, da gestão de pessoas, onde pessoas capacitadas e qualificadas sobre o assunto puderam promover discussões e propor melhorias para todo o ecossistema. 


\section{SISTEMA DE GESTÃO AMBIENTAL}

A gestão ambiental compreende um conjunto de políticas, instruções, programas e práticas operacionais e administrativas voltadas para a saúde e a segurança de pessoas, assim como a preservação e proteção do meio ambiente, a fim de minimizar ou eliminar os prejuízos ambientais que são decorrentes de práticas das operações empresariais.

As pessoas estão cada vez mais valorizando as marcas e empresas que se preocupam com a natureza e que promovem ações que visam à sustentabilidade. A responsabilidade socioambiental vem sendo alvo de investimentos por parte de muitas organizações empresariais, fazendo com que sua marca seja vista como empresa de ação sustentável voltada às questões ambientais.

Talvez, um dos maiores diferenciais existentes no meio empresarial sejam as empresas com ações sustentáveis mostrarem como é possível crescer, produzir e vender, cada vez mais, respeitando os recursos naturais, uma vez que tais recursos são finitos e a utilização adequada e moderada das riquezas ambientais é indispensável para a relação harmoniosa entre os seres vivos.

Muitas são as organizações que procuram obter a Certificação ISO, para que possam ser vistas e reconhecidas como organizações sustentáveis e que valorizam o meio ambiente. Os certificados ISO 9000 e ISO 14000 são os mais desejados; o primeiro se refere à qualidade dos produtos, processos e serviços da empresa e o segundo, à gestão da qualidade ambiental.

O quadro 3 traz uma breve comparação entre o propósito e a direção existentes nas ISO 9000 e ISO 14000, assim como apresenta a particularidade e função de cada uma delas.

Quadro 3 - ISO 9000 versus ISO 14000

\begin{tabular}{|l|l|}
\hline \multicolumn{1}{|c|}{ ISO $\mathbf{9 0 0 0}$} & \multicolumn{1}{c|}{ ISO $\mathbf{1 4 0 0 0}$} \\
\hline $\begin{array}{l}\text { Propósito: atender à necessidade do } \\
\text { cliente. }\end{array}$ & $\begin{array}{l}\text { Propósito: atender às necessidades } \\
\text { da sociedade para a proteção do meio } \\
\text { ambiente. }\end{array}$ \\
\hline Dirigido: à qualidade do produto. & Dirigido: ao meio ambiente. \\
\hline
\end{tabular}

Fonte: Desenvolvido pelo autor (2019). 
A influência da gestão de pessoas nas organizações diante dos impactos ambientais e da sustentabilidade

A ISO 9000 proporciona empresas de todo o mundo a garantirem a entrega de produtos com a melhor qualidade e visa garantir maior qualidade nos processos de produção das empresas, sendo conhecida como o conjunto de padronizações e normas que trata da implementação de processos de Gestão da Qualidade e Garantia da Qualidade.

Tem como objetivo o processo e não o produto, ou seja, garantir que os procedimentos de produção estejam de acordo para assegurar a qualidade do produto, e é formada pelas normas 9001, 9004 e 19011. ISO 9001 - responsável pelas orientações sobre a qualidade dos projetos, desenvolvimento, produção, instalação e manutenção. Aponta como deve ser cada processo.

ISO 9004 - responsável pelas diretrizes para o sucesso sustentado, orientações para a implantação do sistema de gestão de qualidade.

ISO 19011 - responsável pelas diretrizes para auditorias de sistema de gestão.

A certificação ISO 9000 proporciona vantagens competitivas diante dos concorrentes que não possuem esta certificação, promovendo maior fluidez dos processos internos, satisfação dos clientes e a melhora da imagem empresarial.

A ISO 14000 é constituída por normas que determinam diretrizes para assegurar que as empresas pratiquem a gestão ambiental. Tem como principal objetivo garantir a proteção e o equilíbrio ambiental, evitando potenciais riscos e problemas que poderiam ser trazidos para a sociedade e a economia.

O Certificado ISO 14000 garante que determinada empresa está comprometida com as leis ambientais previstas na legislação ambiental do país onde se encontra em atividade. A empresa com essa certificação está obrigada a treinar e qualificar seus colaboradores para seguirem todas essas normas, procurando e identificando soluções para a minimização dos impactos ambientais. A ISO 14000 é composta pelas normas 14001, 14004, 14010, 14031, 14020 e 14040.

ISO 14001 - responsável pelo Sistema de Gestão Ambiental (SGA). ISO 14004 - responsável pelo SGA interno das empresas. 
ISO 14010 - responsável pelas normas de Auditorias Ambientais, assegurando a credibilidade ao processo de certificação.

ISO 14031 - responsável pelas normas de Desempenho Ambiental.

ISO 14020 - responsável pelas normas de Rotulagem Ambiental.

ISO 14040 - responsável pelas normas de Análise do Ciclo de Vida.

Por meio da configuração alinhada dessas ferramentas, convencionou-se chamar de Sistema de Gestão Ambiental. Um dos meios mais utilizados pelas organizações para a obtenção desse sistema é a norma ISO 14001. Para as empresas que desejam comercializar seus produtos no mercado globalizado, a certificação ISO 14001 é um requisito indispensável.

A ISO 14001 é uma norma de sistema que reforça o enfoque no aprimoramento da conservação ambiental pelo uso de um único sistema de gerenciamento permeando todas as funções da organização, não estabelecendo padrões de desempenho ambientais absoluto. Os princípios enunciados possibilitam o estabelecimento de uma visão integrada da gestão ambiental em uma organização. Embora seus enunciados apresentemum caráter amplo, eles possibilitam o embasamento de linhas de ação integradas, as quais levam à operacionalização de um Sistema de Gestão Ambiental (SEIFFERT, 2005, p. 32).

Para ser destaque diante da globalização, as empresas devem se adequar às normas de sustentabilidade, não podendo existir monopólio sobre as questões relacionadas à sustentabilidade ambiental.

\section{METODOLOGIA}

Para a realização desta pesquisa, foram consultados acervos bibliográficos (livros, materiais de estudo de caso, artigos científicos) e demais materiais de referenciais teóricos. Trata-se de uma pesquisa descritiva, envolvendo análise de literaturas sobre a gestão de pessoas, voltada para o desenvolvimento de ações sustentáveis, junto a uma educação ambiental efetiva dentro das organizações, a fim de promover a educação ambiental empresarial para que métodos de conscientização e responsabilidade possam ser aplicados.

Conforme Gil (2002, p. 3), é possível destacar a importância da pesquisa bibliográfica, uma vez que esta se encontra no fato de: 
A influência da gestão de pessoas nas organizações diante dos impactos ambientais e da sustentabilidade

[...] permitir ao investigador a cobertura de uma gama de fenômenos muito mais ampla do que aquela que poderia pesquisar diretamente. Essa vantagem torna-se particularmente importante quando o problema de pesquisa requer dados muito dispersos pelo espaço. Por exemplo, seria impossível a um pesquisador percorrer todo o território brasileiro em busca de dados sobre população ou renda per capita; todavia, se tem a sua disposição uma bibliografia adequada, não tem maiores obstáculos para contar com as informações requeridas. A pesquisa bibliográfica também é indispensável nos estudos históricos. Em muitas situações, não há outra maneira de conhecer os fatos passados se não com base em dados bibliográficos.

\section{CONCLUSÕES}

Com base no levantamento de dados dos referenciais teóricos, foi possível identificar que a gestão de pessoas ainda não se faz presente em todas as organizações, no que diz respeito à sustentabilidade ambiental. De acordo com alguns pesquisadores, ainda existem empresários com o entendimento de que uma gestão de pessoas voltada para questões ambientais é um custo desnecessário, que não proporciona melhorias na sua empresa.

Porém é nítido que os empresários que almejam estar em situação de destaque estão investindo na implantação de uma gestão de pessoas participativa e ativa, defendendo a ideologia de que pessoas são a maior fonte de riqueza que uma empresa pode ter. Para que o capital intelectual de uma organização seja visto e reconhecido, nada melhor que investir no capital humano, proporcionando o desenvolvimento profissional para que o intelectual seja elevado.

É preciso que as políticas de educação ambiental sejam inseridas no contexto das organizações empresariais no que diz respeito a treinamento e desenvolvimento; o desenvolvimento do capital humano e intelectual deve se dar também junto às questões ambientais para uma educação ambiental empresarial estruturada.

Os empresários precisam ter consciência de que as ações dos seus colaboradores são o reflexo da política implantada nas organizações, e é justamente esse comportamento negativo que vai se refletir em meio à 
sociedade. A capacitação pretende preparar o colaborador, mas essa preparação não se resume apenas à esfera profissional, existem as esferas social e pessoal. Para que as empresas sejam capazes de se destacar no mercado competitivo e ainda ser sustentáveis, elas precisam estar compostas por pessoas que se identifiquem com as propostas sugeridas.

Ainda, com relação à educação ambiental empresarial, é necessário que ela esteja enraizada às metas organizacionais, na missão, no valor e na visão da empresa. Com a fusão entre os objetivos empresariais e a nova ideologia de educação ambiental, haverá um maior envolvimento, no qual essa educação deva se fundir com a essência da empresa, alinhar estratégias e definir como promover a conscientização de preservação do meio ambiente por meio da gestão de pessoas e da educação ambiental.

Ser sustentável é promover a reestruturação dos recursos naturais, que há muito tempo vêm sofrendo com a ação destruidora do homem; é garantir que as gerações futuras gozem das maravilhas da natureza ou, até mesmo, que novas maravilhas surjam para serem comtempladas.

\section{REFERÊNCIAS}

BOHLANDER, George; SNELL, Scott; SHERMAN, Arthur. Administração de recursos humanos. São Paulo: Pioneira Thomson Learning, 2005.

BRASIL. Lei Federal n. 9.795/99, de 27 de abril de 1999. Dispõe sobre educação ambiental. Disponível em: https://www.planalto.gov.br/ccivil_03/leis/19795.htm. Acesso em: 3 jan. 2019.

CASELE, Valéria Crivelaro. A educação ambiental como elemento estratégico para a incorporação da sustentabilidade empresarial: caso Itaipu Binacional margem esquerda/Brasil. 2015. Dissertação (Mestrado em Ciências Ambientais) Universidade Estadual do Oeste do Paraná (UNIOESTE), Toledo, PR, 2015. Disponível em: http://tede.unioeste.br/bitstream/tede/1817/1/Valeria\%20Crivelaro\%20 Casale.pdf. Acesso em: 16 dez. 2018.

CHIAVENATO, Idalberto. Gestão de pessoas. 2. ed. São Paulo: Campus, 2009.

DÉCADA DAS NAÇÕES UNIDAS DA EDUCAÇÃO PARA O DESENVOLVIMENTO SUSTENTÁVEL 2005-2014. 
A influência da gestão de pessoas nas organizações diante dos impactos ambientais e da sustentabilidade

DIAS, Reinaldo. Gestão ambiental: responsabilidade social e sustentável. São Paulo: Atlas, 2011.

FREIRE, Paulo. Pedagogia da autonomia: saberes necessários à prática educativa. São Paulo: Paz e Terra, 2011.

GIL, António Carlos. Como elaborar projetos de pesquisa. São Paulo: Atlas, 2002.

INSTITUTO ETHOS. Instituto Ethos de Empresas e Responsabilidade Social. 2009. Disponível em: http://www.ethos.org.br. Acesso em: 8 jan. 2019.

MARRAS, Jean Pierre. Gestão de pessoas em empresas inovadoras. São Paulo: Futura, 2005.

MEDINA, Naná Mininni. A formação dos professores em Educação Ambiental. In: COORDENAÇÃO-GERAL DE EDUCAÇÃO AMBIENTAL. Panorama da Educação Ambiental no ensino fundamental. Brasília: MEC; SEF, 2001. p. 17-24. Disponível em: http://portal.mec.gov.br/secad/arquivos/pdf/educacaoambiental/panorama. pdf. Acesso em 19 dez. 2018.

MEDINA, Naná Mininni. Educação Ambiental para a sustentabilidade. In: CONGRESSO INTERNACIONAL DE EDUCAÇÃO DO COLÉGIO CORAÇÃO DE JESUS, EDUCAR - UMA PERSPECTIVA HUMANÍSTICA, 1. jun. 1998, Florianópolis. Anais [...]. Florianópolis, 1998.

MOUSINHO, Patrícia. Meio ambiente no século 21: 21 especialistas falam da questão ambiental nas suas áreas de conhecimento. 4. ed. Campinas, SP: Armazém do Ipê, 2008.

RAMOS, Elisabeth Christmann. O processo de constituição das concepções de natureza: uma contribuição para o debate na educação ambiental. Revista Ambiente e Educação, Rio Grande, RS, v. 15, n. 1, p. 67-91, 2010.

SEIFFERT, Mari Elizabete Bernardini. ISO 14001 Sistemas de Gestão Ambiental: implantação objetiva e econômica. São Paulo: Atlas, 2005.

TACHIZAWA, Takeshy. Gestão ambiental e responsabilidade social corporativa: estratégias de negócios focadas na realidade brasileira. 3. ed. São Paulo: Atlas, 2005. 
